\title{
Recycling of Nonwoven Polyethylene Terephthalate Textile into Thermal and Acoustic Insulation for More Sustainable Buildings
}

\author{
David Antolinc 1,*(D) and Kristina Eleršič Filipič ${ }^{2,3}$ \\ 1 Faculty of Civil and Geodetic Engineering, University of Ljubljana, Jamova 2, SI-1000 Ljubljana, Slovenia \\ 2 FILC/Freudenberg, Trata 48, SI-4220 Škofja Loka, Slovenia; kristina.elersic@guest.arnes.si \\ 3 Molecular Biology Laboratory, BIA Separations CRO, Labena Ltd., SI-1000 Ljubljana, Slovenia \\ * Correspondence: david.antolinc@fgg.uni-lj.si
}

Citation: Antolinc, D.; Filipič, K.E. Recycling of Nonwoven Polyethylene Terephthalate Textile into Thermal and Acoustic Insulation for More Sustainable Buildings. Polymers 2021, 13, 3090. https://doi.org/10.3390/ polym 13183090

Academic Editor: Ossi Martikka

Received: 25 August 2021

Accepted: 10 September 2021

Published: 14 September 2021

Publisher's Note: MDPI stays neutral with regard to jurisdictional claims in published maps and institutional affiliations.

Copyright: (c) 2021 by the authors. Licensee MDPI, Basel, Switzerland. This article is an open access article distributed under the terms and conditions of the Creative Commons Attribution (CC BY) license (https:/ / creativecommons.org/licenses/by/ $4.0 /)$.

\begin{abstract}
The construction and building sector is responsible for a large share of energy and material used during the life cycle of a building. It is therefore crucial to apply a circular economy model within the process wherever possible to minimize the impact on the environment. In this paper, the possibility of producing thermal and acoustic boards from industrial nonwoven waste textile is studied and presented. The nonwoven polyester textile obtained directly from the production line in the form of strips and bales was first shredded into smaller fractions and then in the form of pile compressed with a hot press to form compact thermal insulation boards. The first set of specimens was prepared only from waste polyester nonwoven textile, whereas the second set was treated with sodium silicate in order to check the material's reaction to fire performance. The experimental work was conducted to define the acoustic properties, reaction to fire behavior and thermal conductivity of the produced specimens. The obtained results show that the thermal conductivity coefficient of specimens without added water glass dissolution is near to the values of conventional materials used as thermal insulation in buildings. The reaction to fire testing proved that the addition of water glass actually propagates the progressive flame over the entire product. It can be concluded that the presented thermal insulation can be used as an adequate and sustainable solution for building construction purposes.
\end{abstract}

Keywords: textile waste; thermal insulation; sound absorber; sustainability; circular economy; recycling

\section{Introduction}

One of the main challenges and problems of modern society is the ever growing volume of waste generated at all levels and domains of human activity. Another problem is also the increased use of energy resources and the accompanying release of greenhouse gasses such as $\mathrm{CO}_{2}$ among others into the air. The improper use of natural resources, secondary raw materials and energy along with the increasing world population is reflected in severe climate changes, loss of biodiversity, land and water pollution [1,2]. The increased awareness about environmental problems addressed over the past decades has unveiled the need for new sustainable solutions to provide opportunities for the next generation to meet their needs in order to achieve their economic, social and environmental objectives. These new sustainable solutions can be achieved by implementing eco-innovations, so-called green innovations or environmental innovations, at the level of companies and countries with considerable environmental impacts [1].

It is important to note that regulations, market pull, and-less frequently but also very importantly-company size, technology push, competition, management and cost savings are the main eco-innovation triggers studied by Hojnik et al. [3]. It is therefore important to have a clear and complete policy and strategy to tackle environmental problems, such as 
the European Green Deal, which has been developed and published in more documents by the European Commission [2,4-6] in recent years. This is a basis for mobilizing industry for a clean and circular economy that supports the eco-innovation with the primary focus on the sectors that use most resources and have a high potential for establishing circular economy [2]. The construction and building sector has a great potential to increase sustainability as it uses large amounts of materials and consumes approximately $40 \%$ of all produced energy for the operation of building stock. It is therefore essential to improve the energy efficiency of old buildings in order to meet the ambitious plans to minimize the negative impact on the environment. The installation of sufficient thermal insulation on the building envelope and upgrade to the use of renewable energy sources are the main measures to achieve adequate energy efficiency according to the current standards and to reach the goal of climate neutrality by 2050 [2].

Additionally, a shift from the linear to circular economy plays an important role in achieving this goal. In order to remain in line with the European Green Deal and to reduce the intensive use of raw materials in construction and the building industry, it is crucial to apply circular economy model to ensure that the largest possible amount of secondary raw materials is used for the construction of new and renovating of old buildings $[1,2,7,8]$.

Polyester or specifically polyethylene terephthalate (PET) accounts for a large part $(18 \%)$ of the global polymer production and around $70 \%$ of all polyester produced is used for fiber applications. In view of the urgent need to find the solution for high volumes of textile waste, the main goal of the present study was to demonstrate the possibility of using industrial waste nonwoven textile made of pure PET fibers as a secondary raw material for the production of thermal insulation boards suitable for applications in buildings. This concept covers the above discussed circular economy principle and at the same time enables the sustainability of buildings by saving energy within the building envelope and thus minimizing the environmental impact. In collaboration with the industrial partners FILC/Freudenberg, who is a producer of technical nonwoven textile, and waste management company CEP d.o.o. from Slovenia, thermal and sound insulation boards made of nonwoven waste textile were developed and tested. Every year the production line generates a substantial amount, between 1500 and $2000 \mathrm{t}$, of nonwoven polyester waste textile as a result of textile formatting at the end of production process or as probe textile sheets with insufficient quality during set up of the production lines, which is then rolled to bales and finally discarded. Currently, the majority of the generated waste nonwoven textile from the production line is incinerated for energy recovery, which is a source of $\mathrm{CO}_{2}$ release and an additional cost for the company. The waste nonwoven textile directly from the production line is made of high-quality PET fibers without external dirt and is as such an ideal secondary raw material that can be used to manufacture profitable products.

This is in contrast to apparel waste textiles which are usually composed of two or more materials, such as cotton, polyester, wool, linen, silk and acrylic, where more effort is needed to recycle these materials and use them as secondary raw materials [9]. However, several authors have presented the attempts to produce thermal and noise insulation made of waste apparel textile [9-22]. There are different mechanical and chemical recycling processing technologies available for waste textiles [23]. In direct mechanical methods, the waste textile is first cut into smaller fractions without converting fabrics back into fibers. These smaller fractions can be directly blown into the air gap of an external double masonry wall system as an effective thermal insulation [9] or it has a potential as an insulation material of light timber frame walls and roofs. Trajković et al. [13] have produced and investigated the thermal insulation blankets made of shredded nonwoven polyester apparel textile encased with the $100 \%$ polypropylene nonwoven fabric which was stabilized by stitching. To produce thermal insulation materials from waste textile, a nonwoven processing technique requires more processing energy input as the waste fabric must be decomposed down to separate fiber or polymer that is recycled from textile waste. Loose recycled fibers are then used within the standard methods of producing nonwoven textiles $[15,16,24]$. As tested by several researchers $[11,25,26]$, insulation materials can also be produced as 
composites by applying heat and pressure [24]. They all have in common that they used mixed waste textile such as nylon and polyurethane [26] or polyester and polyurethane [11] and various other materials and combinations $[20,24,25]$ with or without nonwoven fabric encasing. Another more advanced option for recycling of polymeric waste plastic is chemical method applying the depolymerization with technologies such as hydrolysis, glycolysis, methanolysis, ammonolysis and aminolysis. For the chemical recycling of polyester PET material, including the polyester nonwoven textile, the depolymerization by the glycolysis of diethylene glycol can be effectively used $[27,28]$. This is a process where the glycolized PET oligomers are first reacted with glycerol to produce polyols, which can be further used to produce polyurethane foam via the reaction between produced polyols and polymeric methylene-4, $4^{\prime}$-diphenyl diisocyanate [27]. The final product is a high quality thermal insulation (polyurethane foam) produced from the waste PET fibers or textile. One of the options for textile waste application is also to use it as a filler or reinforcement of organic or inorganic matrices, as described by Patti et al. [29] and Tedesco et al. [30], to improve mechanical characteristics of the produced composites. A successful attempt to use shredded polyester waste textile as aerating agent in the production of aerated clay bricks has also been studied by Tedesco et al. [30]. This shows that there is great interest in finding a solution for waste textile, as it is one of the main sources of waste with 5.8 million tons discarded by consumers each year in Europe alone. Roughly $75 \%$ of this waste is incinerated or landfilled and the remaining small proportion of $25 \%$ is recycled [9,31].

When processing the nonwoven polyester waste textile, the problem was faced while shredding it into smaller fractions due to the large forces needed to tear it, which can result in temperature rise and consequently melting of the material. This problem was also previously addressed by Trajković et al. [13], who suggested that a two-stage shredder with a special knife must be used to avoid this problem. The fractured waste textile was then further processed with a hot press to obtain compact novel semi rigid thermal insulation boards. There are also some options to significantly improve the thermal performance of raw polyester fibers such as impregnation of fibers with silica aerogel particles, such as presented by Lucci et al. [32,33]. There is also great potential to improve the thermal performance of the shredded waste nonwoven polyester textile in the future research. Based on the conclusion of previous authors [34-36] that the addition of water glass could improve the fire resistance of the end product, half of the specimens were treated with a water glass to check the potential beneficial effect on our products. In the following Sections, the methods to identify the material thermal conductivity coefficient, acoustic and fire properties are presented together with the results obtained on the produced thermal insulation boards.

\section{Materials and Methods}

\subsection{Nonwoven Polyester Waste Textile}

Polyester fibers are widely used for the production of nonwoven industrial textile in the form of sheets or continuous fabric (layer, strip), which is then rolled to the bales at the end of the production process. Short polyester fibers are first spread out in the form of a sheet or web and then bound together with one of the three options. The most commonly used is the mechanical bonding of fibers, whereby they are interlocked with serrated needles. The other two options are binding the fibers with adhesive or thermally with an increase in temperature to melt the binder, where the binder is the additional polymer added to the fibers and binds the fibers together after melting at elevated temperature. After production and prior to rolling to a bale, the fabric is usually formatted to the standard desired dimension (width), which is also the source of the relatively large amount of nonwoven textile waste at the production line. Another source of waste at the production line is related to the change of parameters such as density of the nonwoven textile where usually the initial product does not meet the required parameters and quality. Therefore, this nonwoven textile, which is produced during the setup process, is directly rolled to a bale and discarded. Both sources of nonwoven textile waste from the industry are 
clean, free of organic substances and relatively homogenous in terms of material, which makes them suitable for direct recycling into a high-quality product. For the purpose of the present study the discarded waste polyester nonwoven textile was provided by the industrial partner and producer of technical nonwoven textile FILC/Freudenberg. Rolls and bales of discarded waste polyester nonwoven textile were taken randomly from the company's waste storage shown in the left Figure 1. To provide the representative sample of waste polyester textile, approximately 3 tons of material were processed in a two stage shredder to obtain the waste material fractions with the size from 1.5 to $3 \mathrm{~cm}$, as shown in the right Figure 1.
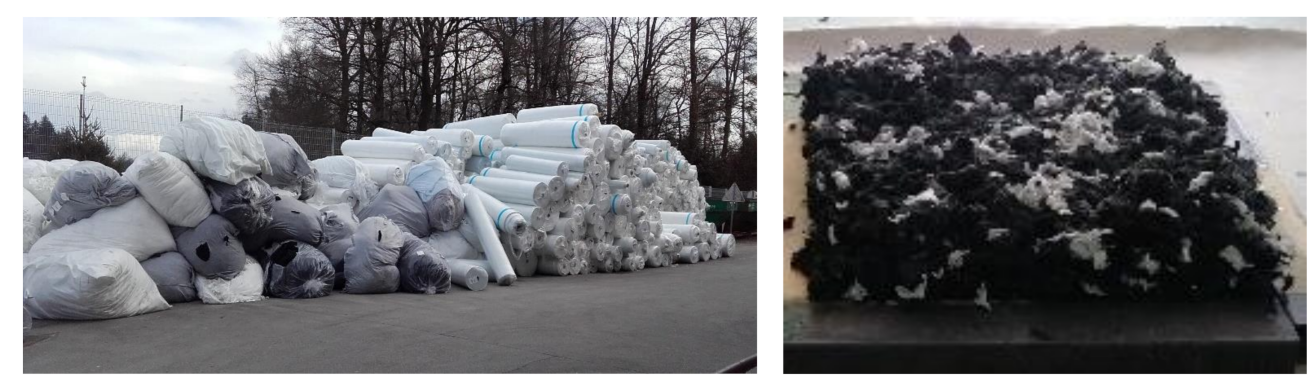

Figure 1. The discarded nonwoven polyester textile at the company's waste storage (left) and shredded waste polyester nonwoven textile prepared for further processing and manufacturing (right).

\subsection{Water Glass}

A sodium silicate or water glass is part of the soluble silicates family and is one of the most versatile inorganic chemicals available [36]. Water glass is produced by melting a mixture of caustic soda $(\mathrm{NaOH})$ and quartz sand $\left(\mathrm{SiO}_{2}\right)$ with the end product of sodium metasilicate $\left(\mathrm{Na}_{2} \mathrm{SiO}_{3}\right)$. Water glass is usually in the form of transparent solid, white powder or soluble in water as viscous liquid with a 25 to $28 \mathrm{wt} \% \mathrm{SiO}_{2}$ and 6 to $18 \mathrm{wt} \% \mathrm{Na}_{2} \mathrm{O}$. Water glass is widely used in industry as fireproofing and adhesive agent in building materials. For this reason, commercially available soluble sodium metasilicate (Samson Kamnik, Slovenia) in form of viscous liquid was applied with a watering sprayer on the waste polyester flakes to test the fire behavior of the produced thermal insulation.

\subsection{Method and Process of Thermal Insulation Production}

The basic component of the produced thermal insulation slab specimens in this study was shredded nonwoven waste polyester textile obtained from the company FILC/ Freudenberg. The nonwoven waste textile was first shredded with a two-stage shredder into the particle size between 1.5 and $3 \mathrm{~cm}$, which were further used to produce two types of insulation slabs. In the first type of slab (designation B1-B8) only shredded nonwoven textile was used without any other substance and in the second type (designation WG1WG8) water glass was added to the surface of the shredded nonwoven textile particles. The designed dimensions of specimens were $30 \mathrm{~cm} \times 30 \mathrm{~cm} \times 3 \mathrm{~cm}$ and $30 \mathrm{~cm} \times 30 \mathrm{~cm} \times 5 \mathrm{~cm}$ for the specimens B1-4, WG1-4 and B5-8, WG5-8 respectively.

When preparing the specimens, the main control parameter was density, which was controlled with the mass of shredded nonwoven textile used for the production of thermal insulation slab. The masses of 300,400, 500 and $700 \mathrm{~g}$ were used as the initial amount of shredded nonwoven textile to produce the thermal insulation slabs of different thicknesses and types. The composition details for each produced specimen are summarized in Table 1.

In the first step of the insulation slab production, the intact nonwoven textile was placed on the table. In the next step, a formwork made of steel profile with the designed final insulation thickness was placed over the intact nonwoven textile. Then the prepared mixture of shredded nonwoven textile with correspondingly defined mass was added into the prepared formwork. The specimen was finally covered by the intact nonwoven textile sheet which provided, after thermal treatment, the reinforcement and smooth top and bottom outer surfaces of the end product. 
Table 1. Composition, thickness and final density of the produced thermal insulation slab samples.

\begin{tabular}{ccccc}
\hline Sample & $\begin{array}{c}\text { Mass of the } \\
\text { Waste } \mathbf{( g )}\end{array}$ & $\begin{array}{c}\text { Mass of the } \\
\text { Water Glass } \mathbf{( g )}\end{array}$ & $\begin{array}{c}\text { Designed } \\
\text { Thickness } \mathbf{( c m})\end{array}$ & Density $\mathbf{( k g / \mathbf { m } ^ { \mathbf { 3 } } )}$ \\
\hline B1 & 300 & 0 & 3 & 123 \\
B2 & 400 & 0 & 3 & 155 \\
B3 & 500 & 0 & 3 & 176 \\
B4 & 700 & 0 & 3 & 226 \\
B5 & 300 & 0 & 5 & 85 \\
B6 & 400 & 0 & 5 & 102 \\
B7 & 500 & 0 & 5 & 119 \\
B8 & 700 & 100 & 5 & 155 \\
WG1 & 300 & 125 & 3 & 125 \\
WG2 & 400 & 200 & 3 & 164 \\
WG3 & 500 & 100 & 3 & 198 \\
WG4 & 700 & 125 & 5 & 255 \\
WG5 & 300 & 150 & 5 & 85 \\
WG6 & 400 & 200 & 5 & 108 \\
WG7 & 500 & 5 & 129 \\
WG8 & 700 & & & \\
\hline
\end{tabular}

Figure 2 shows the example of the final product.

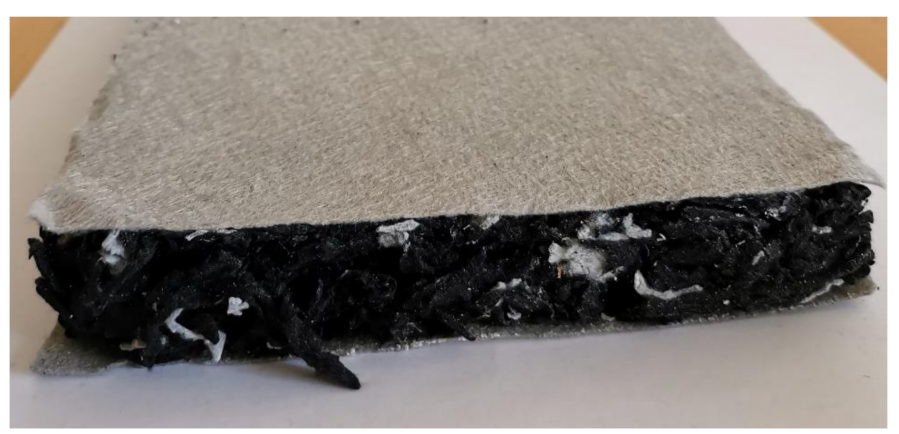

Figure 2. Thermal insulation slab made of shredded compressed waste polyester nonwoven textile.

The specimens prepared in this way were then transported to the preheated press, which is shown in Figure 3. The compression surfaces of the press were preheated to $240{ }^{\circ} \mathrm{C}$ and then compressed down to the steel profile spacer (formwork) which provided us with the desired thickness of the produced thermal insulation slabs. The material was compressed at this temperature for $15 \mathrm{~min}$. The specimens were then taken out of the press and were for further $15 \mathrm{~min}$ left lightly compressed while cooling down before they were further handled. The cooling time is needed for the fibers of nonwoven textile to bond together during the solidifying process of the polyester material. For specimens WG1 to WG8 the water glass was applied first to the bottom nonwoven textile sheet and then to each layer of $100 \mathrm{~g}$ of added shredded nonwoven waste textile. The $25 \mathrm{~g}$ of water glass for each new layer of nonwoven textile was applied with the watering sprayer as it is shown in the left in Figure 3. The end product was a very compact semi rigid insulation slab with a thickness of 3 or $5 \mathrm{~cm}$ encased with the polyester nonwoven textile as shown in Figure 2 . Overview picture of all 16 produced thermal insulation slabs is shown in Figure 4. 

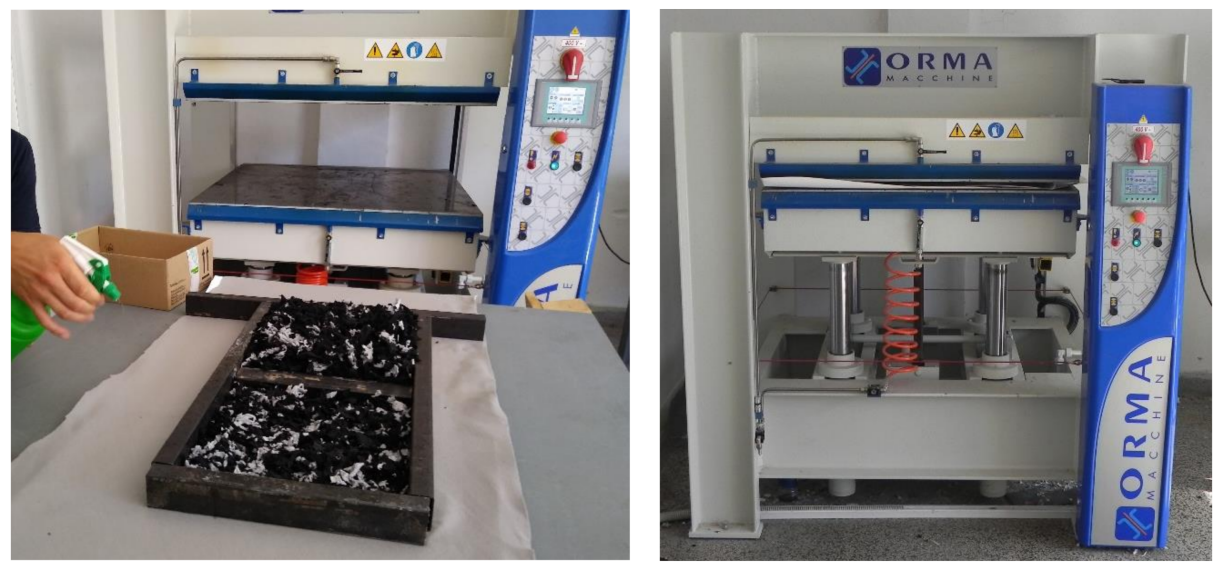

Figure 3. Applying of water glass on the shredded waste nonwoven textile (left) and pressing of the prepared material in the preheated hydraulic press (right).

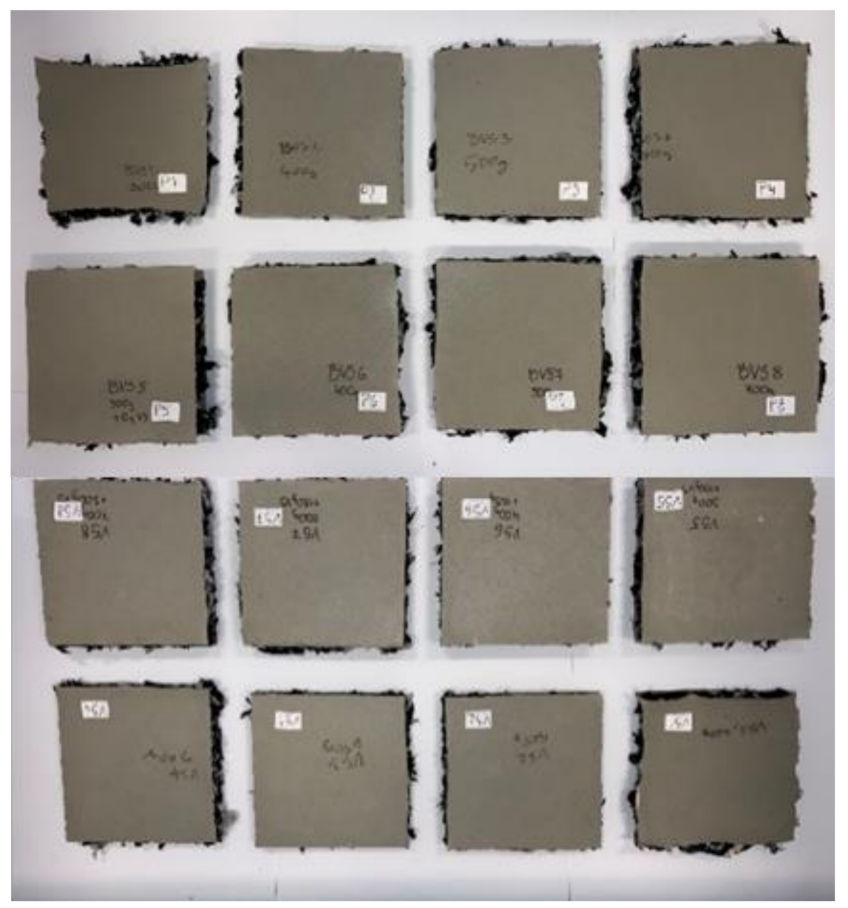

Figure 4. Overview of the produced thermal insulation slab specimens.

\subsection{Experimental Methods}

In order to evaluate the adequacy of the thermal insulation slabs produced from shredded waste nonwoven textile for the purposes of thermal insulation in buildings, thermal conductivity and reaction to the fire test were conducted. Additionally, the acoustic property test was conducted to check the possibility of using the produced thermal insulation slabs as sound absorbers.

\subsubsection{Thermal Conductivity Test}

The main objective of the present research was to identify the possibilities of using the produced insulation boards as thermal insulation for buildings. Therefore, the thermal conductivity test was conducted to obtain the thermal conductivity coefficient $\lambda$.

The thermal conductivity coefficient $\lambda$ of the produced insulation boards with the dimensions of $30 \mathrm{~cm} \times 30 \mathrm{~cm}$ and with the thickness of 3 or $5 \mathrm{~cm}$, was conducted with thermal conductivity test using the method of a heat flow meter according to the standard EN 12667:2002 [37]. The heat flow meter apparatus with a single-specimen symmetrical 
configuration was used, which means that the specimens were placed between the two heat flow meters (AHLBORN, Almemo type 118)(AHLBORN, Holzkirchen, Germany) with a shape of $120 \mathrm{~mm} \times 120 \mathrm{~mm}$ rectangular plate, which can also measure the contact temperature of the specimen surface. To establish a constant steady heat flow through the specimen, a thermo-electrical aluminum heating plate was placed on one side and the heat sink on the opposite side of the specimen. On the hot side of the specimen, the temperature was set to $35^{\circ} \mathrm{C}$ and on the cold side to $25^{\circ} \mathrm{C}$ to achieve the temperature difference of $10{ }^{\circ} \mathrm{C}$, which ensured the steady heat flow through the specimen.

\subsubsection{Reaction to Fire Test}

In order to define the burning behavior of the produced insulation boards, the reaction to fire test was conducted according to the standard EN ISO 11925-2 [38]. With this standard testing procedure, the ignitability of building products directly subjected to the impingement of flame is tested. Specimens of a rectangular shape with the dimensions of $250 / 90 \mathrm{~mm}$ were prepared as required by the standard. Specimens were further suspended vertically and directly impinged with a small flame at an angle of $45^{\circ}$ to the specimen for $15 \mathrm{~s}$ at the bottom edge, as shown in Figure 5. The behavior of the specimen is observed during the exposure to the flame and after removal from the specimen for $20 \mathrm{~s}$.

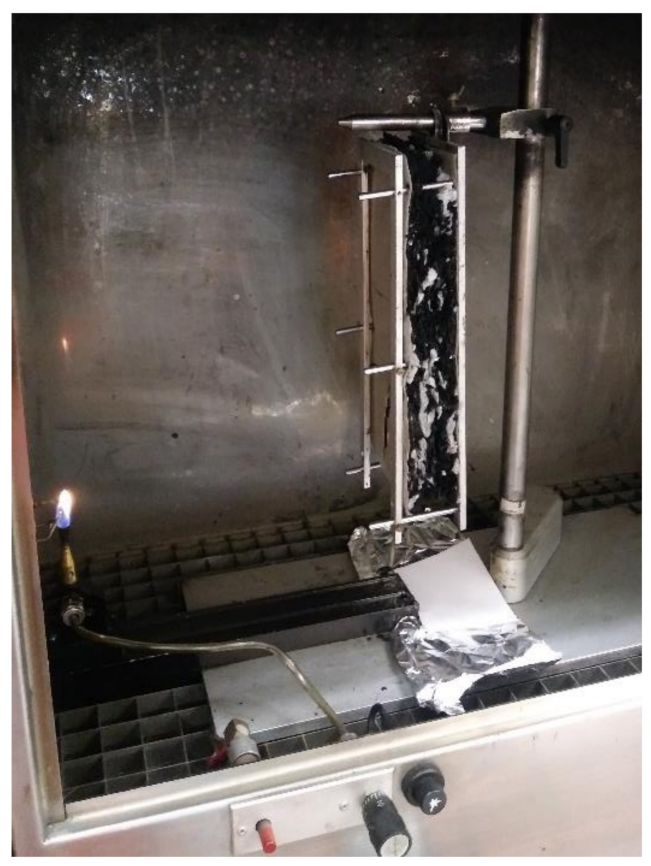

Figure 5. Reaction to fire test set-up for thermal insulation specimens according to the standard ISO 11925-2:2020 [38].

To classify the specimen into class E, the potential burning of the specimen should extinguish within $20 \mathrm{~s}$ after the flame removal and the flame spread should not exceed $150 \mathrm{~mm}$ limit marked along with the height of the specimen. To check the potential for the formation of burning drops from the specimens, the filter paper was placed under the specimen, which would ignite upon contact with a burning drop from the tested specimen.

\subsubsection{Sound Absorption Test}

Thermal insulation boards usually also act as a sound absorbing layer in the building element. Incident sound waves on the building element or partition are partly reflected, transmitted or absorbed. Noise reduction with the absorption of the incident sound wave is very effective and therefore it is important to define the sound absorption coefficient $\alpha$ of the insulation boards. In this research, the method with impedance tube, two microphones and 
digital frequency analyzing system was used according to the standard ISO 10534-2 [39] to determine the sound absorption coefficient for the standard specimens for normal sound incidence. An impedance tube testing instrument from the manufacturer Brüel and Kjaer (Naerum, Denmark) was used with a large tube set-up as shown in Figure 6. Therefore, the specimens with a diameter of $98.5 \mathrm{~mm}$ were prepared to place them in the large tube set-up. The test was conducted for the sound frequency range between 125 and $4000 \mathrm{~Hz}$. The specimens for this test were prepared only from the insulation boards with a thickness of $30 \mathrm{~mm}$ because of the problems with the disintegration of $50 \mathrm{~mm}$ thick specimens when cut them into a circular shape with a diameter of $98.5 \mathrm{~mm}$.
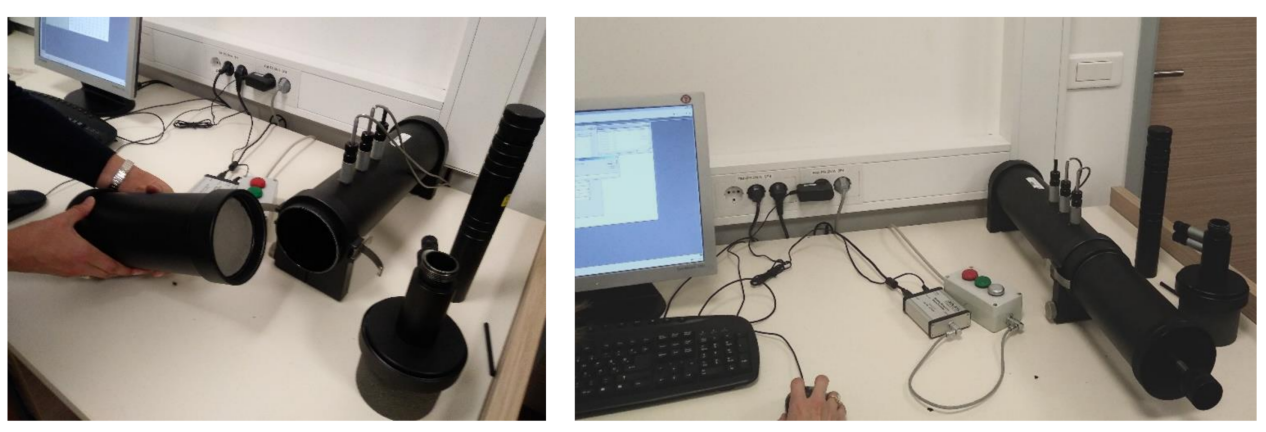

Figure 6. Open impedance tube with the inserted specimen (left) and assembled impedance tube ready to conduct the experiment (right).

\section{Results and Discussion}

\subsection{Thermal Conductivity Coefficient $\lambda$}

The relationship between the density of the produced thermal insulation boards and the thermal conductivity coefficient $\lambda$, for the specimens with 30 and $50 \mathrm{~mm}$ thickness is shown in Figures 7 and 8, respectively. It is obvious that when increasing the density of the produced thermal insulation boards, the thermal conductivity coefficient $\lambda$ increases almost linearly along with it. This is due to the lower air proportion within the specimen, which was achieved with increased density and makes the conductive heat transfer through fibers more prominent.

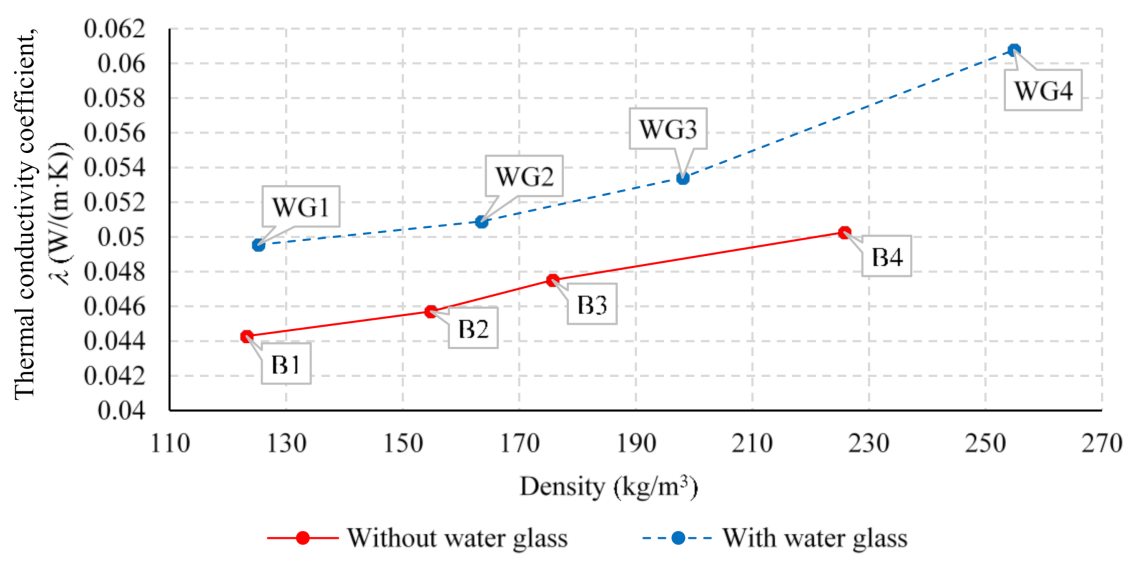

Figure 7. Relationship between thermal conductivity coefficient $\lambda$ and density of the produced thermal insulation boards for specimens with a thickness of $30 \mathrm{~mm}$ with and without added water glass. 


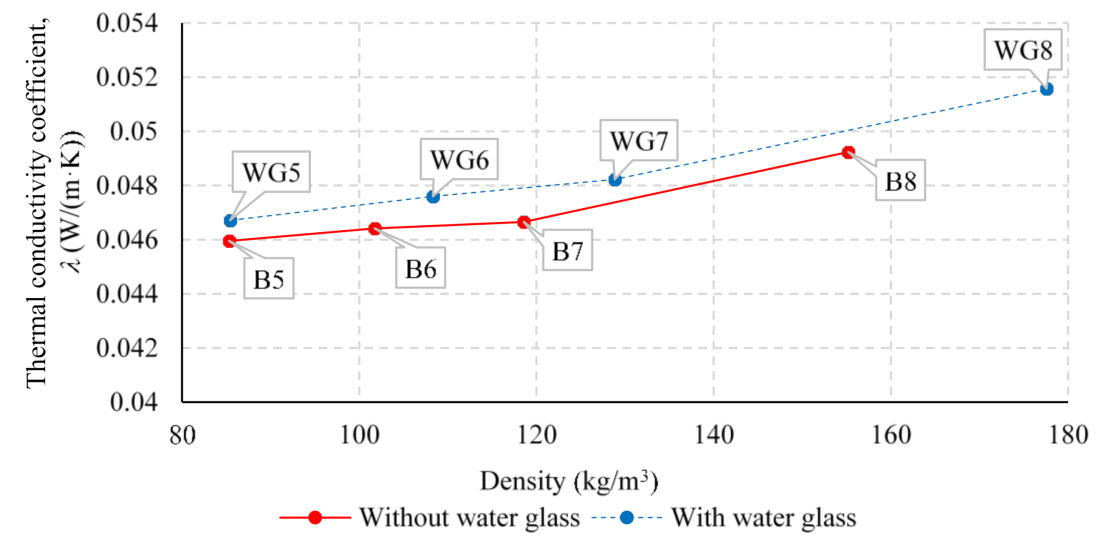

Figure 8. Relationship between thermal conductivity coefficient $\lambda$ and density of the produced thermal insulation boards for specimens with a thickness of $50 \mathrm{~mm}$ with and without added water glass.

The thermal conductivity coefficient $\lambda$ of the specimens without the application of water glass ranged between 0.044 and $0.050 \mathrm{~W} /(\mathrm{m} \cdot \mathrm{K})$, corresponding to the density range between 85.3 and $225.8 \mathrm{~kg} / \mathrm{m}^{3}$. For the specimens with the application of water glass during the production of the specimen, a similar relationship can be observed, where the thermal conductivity coefficient $\lambda$ ranges from 0.047 to $0.061 \mathrm{~W} /(\mathrm{m} \cdot \mathrm{K})$ for the corresponding density, which is within the range of 85.4 and $254.9 \mathrm{~kg} / \mathrm{m}^{3}$. It is also clear that with the application of water glass during the production process of $30 \mathrm{~mm}$ thick specimens, the thermal conductivity coefficient $\lambda$ increases by an average of $0.005 \mathrm{~W} /(\mathrm{m} \cdot \mathrm{K})$ compared to the specimens without added water glass. At the same time, a smaller increase in thermal conductivity coefficient $\lambda$ can be observed when adding the water glass during the production process of $50 \mathrm{~mm}$ thick specimens, on average by $0.001 \mathrm{~W} /(\mathrm{m} \cdot \mathrm{K})$.

\subsection{Fire Resistance Property}

Within this research, special attention was paid to the reaction to fire of the produced thermal insulation. As mentioned above, two types of thermal insulation boards were produced simultaneously, where one type was treated with water glass application during production. The main reason for treating the specimens with water glass was to enhance their fire resistance and also the bonding between the shredded nonwoven waste textile fractions.

The results of the reaction to fire test are shown in Tables 2 and 3 for the 30 and $50 \mathrm{~mm}$ thick specimens, respectively. The specimens without water glass application tend to have shorter ignition time and show less potential for the appearance of flaming droplets in comparison to the specimen with water glass treatment. However, nonwoven polyester textile proved to be self-extinguishing when exposed to a small open flame, as the material first shrinks and then melts. This melted product consequently extinguishes the flame and the temperature drops, which prevents the appearance of flaming droplets. None of the specimens without added water glass (B1-B8) reached the flame height limit of $150 \mathrm{~mm}$ (Figure 9) according to the standard. However, the $50 \mathrm{~mm}$ thick specimens with water glass application WG5, WG6 and WG7 are missing in Figure 9 because they burned out completely and in the case of specimen WG8, the flame almost reached the control limit at the specimens' height of $150 \mathrm{~mm}$.

The flame on the thinner specimens with water glass application WG1-WG4 was stronger than on specimens B1-B4 without water glass. The results of the reaction to fire test clearly show an unfavorable behavior of the specimens with water glass application in comparison to the specimens without water glass, which is in contradiction to some other authors $([35,36,40])$ who have proved that the addition of water glass can improve the fire resistance of their specific application and product. The reason for the unfavorable behavior of specimens with added water glass may be because the application of water glass to the nonwoven textile flakes and fibers locally prevents melting of the material. 
This preserves the structure of thermal insulation with a high proportion of air voids, and also allows the flammable smoke mixed with oxygen to flow with the chimney effect through such specimen. This is then the condition for the severe flame propagation and the complete burning out of the material, as it happened with specimens WG6, WG7, WG8.

Table 2. Resistance to fire properties for the specimens with a thickness of $30 \mathrm{~mm}$.

\begin{tabular}{ccccc}
\hline Specimen & Ignition Time (s) & Flaming Droplet Time (s) & $\begin{array}{c}\text { Flame Reaching the } \\
\text { Reference Line Time (s) }\end{array}$ & $\begin{array}{c}\text { Fire Extinguishing } \\
\text { Time (s) }\end{array}$ \\
\hline B1 & 2 & $/$ & $/$ & 40 \\
B2 & $/$ & $/$ & $/$ & $/$ \\
B3 & 15 & $/$ & $/$ & $/$ \\
B4 & $/$ & 22 & $/$ & 27 \\
WG1 & 3 & 55 & $/$ & 60 \\
WG2 & 10 & $/$ & $/$ & 30 \\
WG3 & 15 & 30 & & 69 \\
WG4 & 13 & & & \\
\hline
\end{tabular}

Table 3. Resistance to fire properties for the specimens with a thickness of $50 \mathrm{~mm}$.

\begin{tabular}{ccccc}
\hline Specimen & Ignition Time (s) & Flaming Droplet Time (s) & $\begin{array}{c}\text { Flame Reaching the } \\
\text { Reference Line Time (s) }\end{array}$ & $\begin{array}{c}\text { Fire Extinguishing } \\
\text { Time (s) }\end{array}$ \\
\hline B5 & 3 & 10 & $/$ & 25 \\
B6 & 5 & $/$ & $/$ & 28 \\
B7 & 14 & 22 & $/$ & $/$ \\
B8 & $/$ & $/$ & 90 & $/$ \\
WG5 & 5 & 10 & 120 & $/$ \\
WG6 & 7 & 13 & 130 & 132 \\
WG7 & 5 & 15 & $/$ & $/$ \\
WG8 & 13 & 24 & & $/$ \\
\hline
\end{tabular}

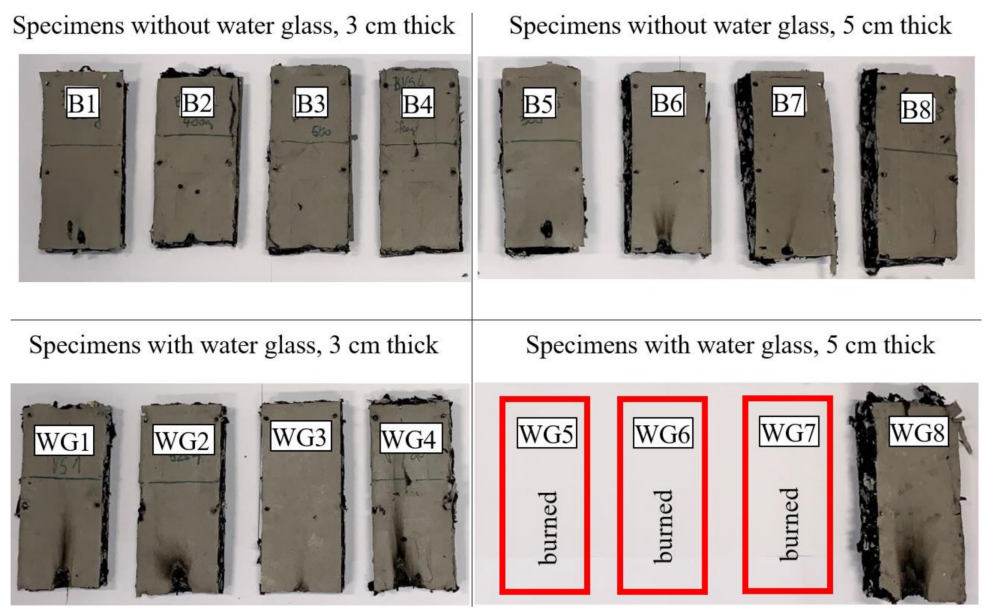

Figure 9. Specimens of thermal insulation boards after reaction to fire test.

From the experimental results, it can be concluded that in our case the treatment of the shredded polyester nonwoven textile with the addition of water glass negatively affects the fire resistance properties and therefore there is no benefit for its use.

\subsection{Acoustic Properties}

It is always beneficial for thermal insulation boards if they possess good acoustic properties. Therefore, we evaluated the sound absorption coefficient $\alpha$ for the octave range from 125 to $4000 \mathrm{~Hz}$, which is a standardized evaluation range for building materials. 
The frequency dependent results of the sound absorption coefficient $\alpha$ for $30 \mathrm{~mm}$ thick specimens are shown in Figure 10.

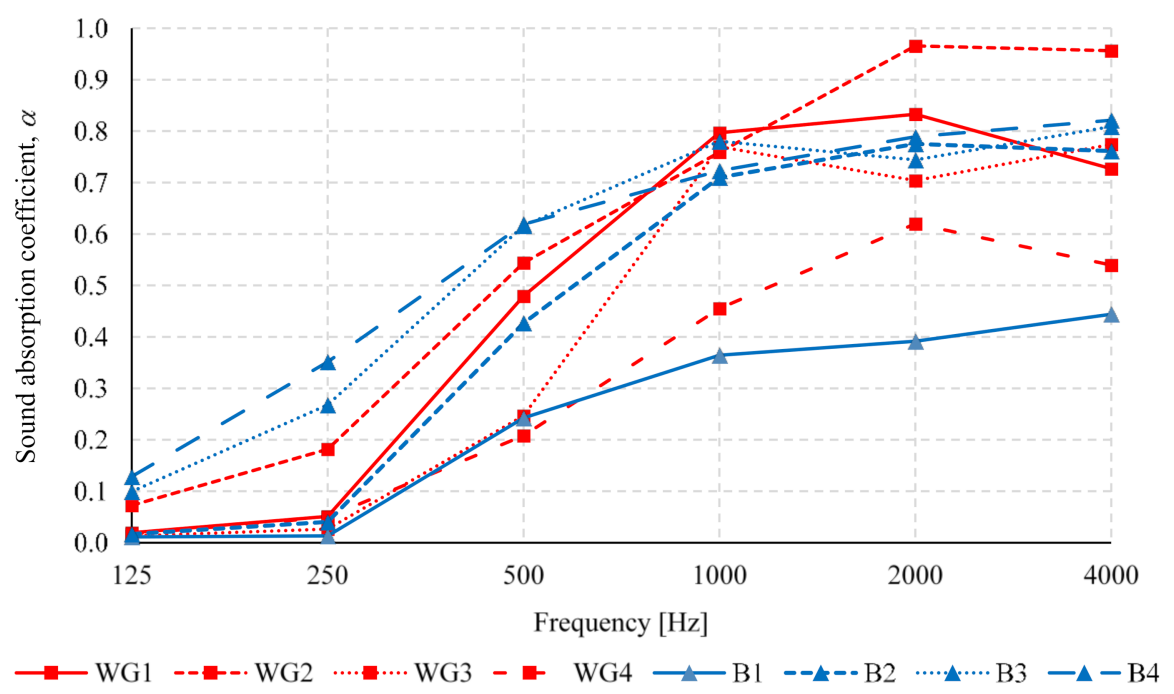

Figure 10. Sound absorption coefficient $\alpha$ of thermal insulation boards made of waste nonwoven textile for the octave range frequencies.

For all tested specimens the $\alpha$ values at $125 \mathrm{~Hz}$ are below 0.15 , which is an expected result for a thin fibrous material. With the specimens without water glass (B1-B4), a density dependent increase in sound absorption properties of specimens is observed. Specimen B1 with the lowest density $\left(123 \mathrm{~kg} / \mathrm{m}^{3}\right)$ showed the worst behavior over the entire frequency range, reaching the highest sound absorption coefficient $\alpha=0.44$ at $4000 \mathrm{~Hz}$. Specimens B1, B2 and B3 show similar absorption properties at 1000 to $4000 \mathrm{~Hz}$ octave bands reaching up to $\alpha=0.80$, and the acoustic performance of the two specimens with the highest densities (B3 and B4) is very favorable already at 250 and $500 \mathrm{~Hz}$. The sound absorption quality of specimens with added water glass (WG1-WG4) similarly improves with frequency. However, the specimens with the lowest density (WG1 and WG2) show the highest $\alpha$ values, unlike the specimens without added water glass. Addition of water glass probably increases the airflow resistivity and affects the sound absorption capability of the material [41].

In addition, we evaluated noise reduction coefficient NRC for all tested specimens given in Table 4. NRC was calculated as an average sound absorption coefficient at octave bands of 250, 500, 1000 and $2000 \mathrm{~Hz}$, which is a scalar representation of the sound absorption performance of the insulation boards. The overall sound absorbing performance of specimens B1, B2, B3 and B4 improves from 0.20 up to 0.60 with an increase in density of the specimens from 123.2 to $225.8 \mathrm{~kg} / \mathrm{m}^{3}$. At the same time, the specimens with added water glass show a different relationship between NRC and density. Specimen WG4 with the highest density has the lowest NRC equal to 0.35 . The difference in the behavior of specimens with or without water glass could be explained by the difference in airflow resistivity of two different materials. For common materials and products, NRC must be greater than 0.2 in order to classify them as sound-absorbing materials [42]. As all specimens show higher NRC than 0.2 , we can conclude that all of the developed thermal insulation boards can be effectively used as sound-absorbing elements. Especially good sound absorbers are those without water glass treatment and with the highest density, or specimens with added water glass at lower densities. 
Table 4. Noise reduction coefficient NRC for the insulation boards with and without water glass application with a thickness of $30 \mathrm{~mm}$.

\begin{tabular}{ccc}
\hline Specimen & Density $\left(\mathbf{k g} / \mathbf{m}^{\mathbf{3}}\right)$ & NRC \\
\hline B1 & 123.2 & 0.25 \\
B2 & 154.8 & 0.50 \\
B3 & 175.7 & 0.66 \\
B4 & 225.8 & 0.66 \\
\hline WG1 & 125.2 & 0.55 \\
WG2 & 163.5 & 0.60 \\
WG3 & 198 & 0.45 \\
WG4 & 254.9 & 0.35 \\
\hline
\end{tabular}

\subsection{Comparison of Developed Insulation Board with Conventional Insulation Materials}

To compare the efficiency of the developed insulation materials within the present study with other conventional materials used for civil engineering applications the Table 5 was prepared. The density, thermal conductivity coefficient $\lambda$ and noise reduction coefficient NRC are summarized and compared. The thermal conductivity coefficient $\lambda$ of the thermal insulation presented in this study is in the range of other conventional thermal insulation materials such as rock wool mats, fiberglass mats and polystyrene boards. The NRC values of the developed insulation slabs are also similar to the conventional fibrous materials and at the same time they show favorable behavior when compared to cellular synthetic materials such as polystyrene. Other researchers $([9,11,13,15,43])$ who have been dealing with the mixed waste textile and various recycling techniques have obtained similar results to the results presented in this study. There is also an option to impregnate the fibers with the aerogel which significantly reduce the thermal conductivity coefficient [33]. This type of thermal insulation is an ideal solution for the internal insulation of outer walls, where it is important to save the available area inside the rooms. However, the thermal insulation slabs made of waste nonwoven polyester textile developed in the present study proved to have adequate characteristics for the purposes of civil engineering applications.

Table 5. Summary of density, thermal insulation coefficient $\lambda$ and noise reduction coefficient NRC for the developed insulation boards and various conventional insulation materials.

\begin{tabular}{|c|c|c|c|c|}
\hline Specimen & Density $\left(\mathrm{kg} / \mathrm{m}^{3}\right)$ & $\begin{array}{l}\text { Thermal Conductivity } \\
\text { Coefficient, } \lambda(W /(m \cdot K))\end{array}$ & NRC & Source \\
\hline B1-B8 & $85-226$ & $0.044-0.05$ & $0.25-0.66$ & \multirow{2}{*}{ This study } \\
\hline WG1-WG8 & $85-255$ & $0.047-0.061$ & $0.35-0.55$ & \\
\hline \multirow{2}{*}{$\begin{array}{c}\text { Mixed textile waste } \\
\text { Polyester fibers impregnated } \\
\text { with aerogel }\end{array}$} & $50-500$ & $0.034-0.08$ & $43-80$ & {$[9,11,13,15,43]$} \\
\hline & $50-70$ & $0.0255-0.0281$ & / & {$[32]$} \\
\hline Rockwool mat & $30-180$ & $0.038-0.039$ & 0.65 & {$[44,45]$} \\
\hline Fiberglass mat & $14-80$ & $0.032-0.038$ & 0.65 & {$[44,45]$} \\
\hline Extruded polystyrene & 33 & $0.035-0.038$ & / & {$[45]$} \\
\hline Polystyrene & $15-30$ & 0.041 & 0.17 & {$[42,45]$} \\
\hline Polyurethane foam & $15-80$ & $0.025-0.040$ & / & {$[45,46]$} \\
\hline
\end{tabular}

\section{Conclusions}

The present study shows the great possibility of recycling industrial waste nonwoven polyester textile. The research was conducted in cooperation with the industrial partner FILC/Freudenberg that manufactures the nonwoven polyester textile and whose production process results in substantial amounts of waste textile. The polyester nonwoven textile was first shredded into smaller fractions that were then in a certain amount placed into a hot press and compressed to partly melt the fibers in order to bind them together into a compact thermal insulation board. Samples with the addition of water glass were 
prepared, which was applied with water spray in layers for the fire retardant and binding purposes. The production process proved to be very suitable for the production of high-quality compact thermal insulation boards. Basic experimental tests of the produced thermal insulation were conducted to check thermal conductivity coefficient, reaction to fire resistance and acoustic properties to justify the possibility of using the considered thermal insulation boards also as sound absorbers. Based on the experimental results, the following conclusions can be drawn:

1. Compact semi rigid thermal insulation boards can be produced with densities ranging from 123.2 to $255 \mathrm{~kg} / \mathrm{m}^{3}$.

2. Thermal conduction testing proved that the specimens without water glass and with the lowest density are suitable for the purpose of providing thermal efficiency in buildings and have thermal conductivity coefficient $\lambda$ values of $0.044 \mathrm{~W} /(\mathrm{m} \cdot \mathrm{K})$. The addition of water glass during the production process had a negative impact on the thermal conductivity coefficient $\lambda$, which increased by 0.005 up to $0.049 \mathrm{~W} /(\mathrm{m} \cdot \mathrm{K})$.

3. The reaction to the fire test has shown that the addition of water glass makes the product more vulnerable to open flame, which is in contradiction to the desired properties. At the same time, the specimens without water glass show a favorable self-extinguishing behavior when exposed to fire.

4. All of the produced specimens have NRC of more than 0.20 and can therefore be classified as sound absorbing products. As expected, they show low sound absorption coefficient $\alpha$ within the low frequency range. NRC increases from 0.20 to 0.60 with the increasing density of the specimen without added water glass. The specimens with the highest density proved to have the sound absorption coefficient between 0.70 and 0.80 at $1 \mathrm{kHz}$ and above.

In conclusion, we have demonstrated that it is possible to produce high-quality thermal and acoustic boards from industrial waste, which is usually clean and high-quality material. The produced insulation boards are also a good example of circular economy and represent a great contribution to the concept of sustainable economy. The produced thermal and acoustic insulation can be effectively used for the insulation of outer walls, and roofs between and below the rafters and partition walls.

Instead of incineration of clean and high-quality waste polyester nonwoven textile that causes pollution and $\mathrm{CO}_{2}$ release, the very same material can be utilized for the thermal insulation of buildings to improve their energy efficiency, while saving additional $\mathrm{CO}_{2}$ release.

Author Contributions: Conceptualization, D.A. and K.E.F.; methodology, D.A. and K.E.F.; validation, D.A.; formal analysis, D.A.; investigation, D.A. and K.E.F.; resources, D.A. and K.E.F.; data curation, D.A.; writing-original draft preparation, D.A.; writing-review and editing, D.A. and K.E.F.; visualization, D.A.; supervision, K.E.F.; project administration, D.A.; funding acquisition, D.A. All authors have read and agreed to the published version of the manuscript.

Funding: This research was funded by Slovenian Ministry of Education, Science and Sport, European Social Fund and Public Scholarship, Development, Disability and Maintenance Fund of the Republic of Slovenia with a grant number 11081-25/2016. The APC was partially funded by the Slovenian Research Agency, Research Program Earthquake Engineering, P2-0185.

Institutional Review Board Statement: Not applicable.

Informed Consent Statement: Not applicable.

Data Availability Statement: All data appear in the submitted article.

Acknowledgments: The work presented in this paper is the result of the cooperation between University of Ljubljana, Faculty of Civil and Geodetic Engineering, the company FILC/Freudenberg and the waste management company CEP d.o.o. Part of the research was done within the project "Reciklaža tekstilnih odpadkov iz filca $z$ namenom izdelave toplotno izolativnega materiala za potrebe $\mathrm{v}$ gradbeništvu". The experimental part of the research was conducted under the author's supervision within the graduation thesis titled "Thermal insulation made from non-woven textile waste" [47] prepared by the candidate Luka Braz. His contribution to this research is gratefully acknowledged. 
Conflicts of Interest: The authors declare no conflict of interest. The funders had no role in the design of the study; in the collection, analyses, or interpretation of data; in the writing of the manuscript, or in the decision to publish the results.

\section{References}

1. García-Granero, E.M.; Piedra-Muñoz, L.; Galdeano-Gómez, E. Eco-Innovation Measurement: A Review of Firm Performance Indicators. J. Clean. Prod. 2018, 191, 304-317. [CrossRef]

2. European Commission. Secretariat-General Communication from the Commission-European Green Deal; Publication Office of the European Union: Luxembourg, 2019.

3. Hojnik, J.; Ruzzier, M. What Drives Eco-Innovation? A Review of an Emerging Literature. Environ. Innov. Soc. Transit. 2016, 19, 31-41. [CrossRef]

4. Directorate-General for Communication (European Commission). Circular Economy Action Plan: For a Cleaner and More Competitive Europe; Publications Office of the European Union: Luxembourg, 2020; ISBN 978-92-76-19070-7.

5. Directorate-General for Environment (European Commission). Report from the Commission to the European Parliament, The Council, The European Economic and Social Committee and the Committee of the Regions on the Implementation of the Circular Economy Action Plan; Publications Office of the European Union: Luxembourg, 2019.

6. European Commission. Communication from the Commission to the European Parliament, The Council, The European Economic and Social Committee and The Committee of The Regions Closing the Loop-An EU Action Plan for the Circular Economy; Publications Office of the European Union: Luxembourg, 2015.

7. Dalhammar, C. Industry Attitudes towards Ecodesign Standards for Improved Resource Efficiency. J. Clean. Prod. 2016, 123, 155-166. [CrossRef]

8. Marcon, A.; de Medeiros, J.F.; Ribeiro, J.L.D. Innovation and Environmentally Sustainable Economy: Identifying the Best Practices Developed by Multinationals in Brazil. J. Clean. Prod. 2017, 160, 83-97. [CrossRef]

9. Briga-Sá, A.; Nascimento, D.; Teixeira, N.; Pinto, J.; Caldeira, F.; Varum, H.; Paiva, A. Textile Waste as an Alternative Thermal Insulation Building Material Solution. Constr. Build. Mater. 2013, 38, 155-160. [CrossRef]

10. Binici, H.; Eken, M.; Dolaz, M.; Aksogan, O.; Kara, M. An Environmentally Friendly Thermal Insulation Material from Sunflower Stalk, Textile Waste and Stubble Fibres. Constr. Build. Mater. 2014, 51, 24-33. [CrossRef]

11. Valverde, I.C.; Castilla, L.H.; Nuñez, D.F.; Rodriguez-Senín, E.; de la Mano Ferreira, R. Development of New Insulation Panels Based on Textile Recycled Fibers. Waste Biomass Valorization 2013, 4, 139-146. [CrossRef]

12. Quartinello, F.; Vecchiato, S.; Weinberger, S.; Kremenser, K.; Skopek, L.; Pellis, A.; Guebitz, G.M. Highly Selective Enzymatic Recovery of Building Blocks from Wool-Cotton-Polyester Textile Waste Blends. Polymers 2018, 10, 1107. [CrossRef]

13. Trajković, D.; Jordeva, S.; Tomovska, E.; Zafirova, K. Polyester Apparel Cutting Waste as Insulation Material. J. Text. Inst. 2017, 108, 1238-1245. [CrossRef]

14. Mondal, M.K.; Bose, B.P.; Bansal, P. Recycling Waste Thermoplastic for Energy Efficient Construction Materials: An Experimental Investigation. J. Environ. Manag. 2019, 240, 119-125. [CrossRef]

15. Patnaik, A.; Mvubu, M.; Muniyasamy, S.; Botha, A.; Anandjiwala, R.D. Thermal and Sound Insulation Materials from Waste Wool and Recycled Polyester Fibers and Their Biodegradation Studies. Energy Build. 2015, 92, 161-169. [CrossRef]

16. El Wazna, M.; El Fatihi, M.; El Bouari, A.; Cherkaoui, O. Thermo Physical Characterization of Sustainable Insulation Materials Made from Textile Waste. J. Build. Eng. 2017, 12, 196-201. [CrossRef]

17. Sayed, U.; Parte, S. Recycling of Non Woven Waste. Int. J. Adv. Sci. Eng. 2015, 1, 67-71.

18. Abdel-Rehim, Z.S.; Saad, M.M.; El-Shakankery, M.; Hanafy, I. Textile Fabrics as Thermal Insulators. Autex Res. J. 2006, 6, 148-161.

19. Orlik-Kożdoń, B. Assessment of the Application Efficiency of Recycling Materials in Thermal Insulations. Constr. Build. Mater. 2017, 156, 476-485. [CrossRef]

20. Lin, C.-M.; Lou, C.-W.; Lin, J.-H. Manufacturing and Properties of Fire-Retardant and Thermal Insulation Nonwoven Fabrics with FR-Polyester Hollow Fibers. Text. Res. J. 2009, 79, 993-1000. [CrossRef]

21. Rubino, C.; Bonet Aracil, M.; Liuzzi, S.; Stefanizzi, P.; Martellotta, F. Wool Waste Used as Sustainable Nonwoven for Building Applications. J. Clean. Prod. 2021, 278, 123905. [CrossRef]

22. Rubino, C.; Bonet Aracil, M.; Gisbert-Payá, J.; Liuzzi, S.; Stefanizzi, P.; Zamorano Cantó, M.; Martellotta, F. Composite Eco-Friendly Sound Absorbing Materials Made of Recycled Textile Waste and Biopolymers. Materials 2019, 12, 4020. [CrossRef]

23. Chemical Recycling: Making Fiber-to-Fiber Recycling A Reality for Polyester Textiles I GreenBlue. Available online: https: //greenblue.org/work/chemical-recycling/ (accessed on 8 September 2020).

24. Islam, S.; Bhat, G. Environmentally-Friendly Thermal and Acoustic Insulation Materials from Recycled Textiles. J. Environ. Manag. 2019, 251, 109536. [CrossRef]

25. Palakurthi, M. Development of Composites from Waste PET-Cotton Textiles. Master's Thesis, University of Nebraska-Lincoln, Lincoln, NE, USA, December 2016.

26. Dissanayake, D.G.K.; Weerasinghe, D.U.; Wijesinghe, K.A.P.; Kalpage, K.M.D.M.P. Developing a Compression Moulded Thermal Insulation Panel Using Postindustrial Textile Waste. Waste Manag. 2018, 79, 356-361. [CrossRef]

27. Luo, X.; Li, Y. Synthesis and Characterization of Polyols and Polyurethane Foams from PET Waste and Crude Glycerol. J. Polym. Environ. 2014, 22, 318-328. [CrossRef] 
28. Borowicz, M.; Isbrandt, M.; Paciorek-Sadowska, J. Effect of New Eco-Polyols Based on PLA Waste on the Basic Properties of Rigid Polyurethane and Polyurethane/Polyisocyanurate Foams. Int. J. Mol. Sci. 2021, 22, 8981. [CrossRef]

29. Patti, A.; Cicala, G.; Acierno, D. Eco-Sustainability of the Textile Production: Waste Recovery and Current Recycling in the Composites World. Polymers 2021, 13, 134. [CrossRef] [PubMed]

30. Tedesco, S.; Montacchini, E. From Textile Waste to Resource: A Methodological Approach of Research and Experimentation Sustainability 2020, 12, 10667. [CrossRef]

31. Tallini, A.; Cedola, L. A Review of the Properties of Recycled and Waste Materials for Energy Refurbishment of Existing Buildings towards the Requirements of NZEB. Energy Procedia 2018, 148, 868-875. [CrossRef]

32. Lucchi, E.; Becherini, F.; Di Tuccio, M.C.; Troi, A.; Frick, J.; Roberti, F.; Hermann, C.; Fairnington, I.; Mezzasalma, G.; Pockelé, L.; et al. Thermal Performance Evaluation and Comfort Assessment of Advanced Aerogel as Blown-in Insulation for Historic Buildings. Build. Environ. 2017, 122, 258-268. [CrossRef]

33. Lucchi, E.; Roberti, F.; Alexandra, T. Definition of an Experimental Procedure with the Hot Box Method for the Thermal Performance Evaluation of Inhomogeneous Walls. Energy Build. 2018, 179, 99-111. [CrossRef]

34. Wang, H.; Sheng, K.; Chen, J.; Mao, H.; Qian, X. Mechanical and Thermal Properties of Sodium Silicate Treated Moso Bamboo Particles Reinforced PVC Composites. Sci. China Technol. Sci. 2010, 53, 2932-2935. [CrossRef]

35. Salim, M.S.; Rasyid, M.F.A.; Abdullah, M.A.; Taib, R.M.; Ishak, Z.A.M. Mechanical, Thermal and Flammability Properties of Nonwoven Kenaf Reinforced Acrylic Based Polyester Composites: Effect of Water Glass Treatment. IOP Conf. Ser. Mater. Sci. Eng. 2018, 368, 012040. [CrossRef]

36. Medina, L.A.; Schladjewski, R. Water Glass as Hydrophobic Additive for Natural Fiber Reinforced Composites. J. Nanostructured Polym. Nanocomposites 2009, 5, 107-114.

37. Spletna Trgovina SIST-SIST EN 12667:2002. Available online: http://ecommerce.sist.si/catalog/project.aspx?id=c479b508-30f0-4 315-aa53-ce8f39252a5f (accessed on 21 August 2020).

38. ISO 11925-2:2020. Reaction to Fire Tests-Ignitability of Products Subjected to Direct Impingement of Flame-Part 2: Single-Flame Source Test; ISO: Geneva, Switzerland, 2020.

39. ISO 10534-2:1998. Acoustics—Determination of Sound Absorption Coefficient and Impedance in Impedance Tubes-Part 2: TransferFunction Method; ISO: Geneva, Switzerland, 1998.

40. Basak, S.; Samanta, K.K.; Chattopadhyay, S.K.; Das, S.; Narkar, R.; Dsouza, C.; Shaikh, A.H. Flame Retardant and Antimicrobial Jute Textile Using Sodium Metasilicate Nonahydrate. Pol. J. Chem. Technol. 2014, 16, 106-113. [CrossRef]

41. Delany, M.E.; Bazley, E.N. Acoustical Properties of Fibrous Absorbent Materials. Appl. Acoust. 1970, 3, 105-116. [CrossRef]

42. Haimei, Z. Building Materials in Civil Engineering, 1st ed.; Woodhead Publishing Limited: Cambridge, England, 2011; ISBN 978-1-84569-955-7.

43. Danihelová, A.; Němec, M.; Gergel', T.; Gejdoš, M.; Gordanová, J.; Sčensný, P. Usage of Recycled Technical Textiles as Thermal Insulation and an Acoustic Absorber. Sustainability 2019, 11, 2968. [CrossRef]

44. Dieckmann, E.; Dance, S.; Sheldrick, L.; Cheeseman, C. Novel Sound Absorption Materials Produced from Air Laid Non-Woven Feather Fibres. Heliyon 2018, 4, e00818. [CrossRef] [PubMed]

45. Učinkovita Raba Energije, TSG-1-004:2010. Available online: https://www.zaps.si/img/admin/file/WWW\%20ZAPS/ARH\%20 1_14/1_14_2\%20Tehnicna\%20smernica_raba\%20energije_TSG-1-004_2010.pdf. (accessed on 7 September 2021).

46. Zhu, X.; Kim, B.-J.; Wang, Q.; Wu, Q. Recent Advances in the Sound Insulation Properties of Bio-Based Materials. BioResources 2014, 9, 1764-1786. [CrossRef]

47. Braz, L. Thermal Insulation Made from Non-Woven Textile Waste. Graduation Thesis, University of Ljubljana, Faculty of Civil and Geodetic Engineering, Ljubljana, Slovenia, 2019. 